\title{
HALLAZGO DE UNA BIBLIOTECA MORISCA EN POTRIES (GANDÍA) EN 1789
}

Por

JUAN BTA. VILAR

No deja de resultar paradójico el hecho de que siendo los moriscos valencianos, con los de Granada, quienes detentaron siempre un superior nivel cultural entre sus correligionarios de España, entendiendo por tal no sólo la fidelidad a la lengua árabe, a los preceptos religiosos islámicos y a las tradiciones ancestrales musulmanas -manifestaciones que se dieron en ellos con mayor pureza e intensidad que entre sus congéneres de otras religiones españolas-, sino también el cultivo de una cultura escrita, sea poco lo que se conoce de sus lecturas, libros y bibliotecas. Menos todavía de su producción literaria, información reducida a escasas y aisladas noticias de primera mano (1), y a las más numerosas pero asistemáticas y harto confusas contenidas en la documentación inquisitorial del Tribunal de Valencia (2) y, en menor medida, del de Murcia y obispado de Orihuela (3).

Infortunadamente los IIbros arabes valencianos se nan perdido en su casi totalidad. Contadísimos son los ejemplares conservados en diferentes fondos

(1) Vid. L.P. MARVEY, "The arabic dialect of Valencia in 1595", Al-Andalus, 36 (1971), ps. 81-115; A.M. ${ }^{\text {a }}$ LABARTA, "Los libros de los moriscos valencianos", Awraq, 2 (1979), ps. 72-80.

(2) LABARTA, "Inventario de los documentos árabes contenidos en procesos inquisitoriales contra moriscos valencianos, conservados en el Archivo Histórico Nacional de Madrid (Legajos 548-556)", Al-Qantara, 1 (1980), ps. 115-164.

LABARTA, "Notas sobre algunos traductores de árabe de la Inquisición valenciana (1565-1609)", Revista del instituto Egipcio de Estudios Islámicos, 21 (1981-82), ps. 105-134: R. GARCIA CARCEL, Herejía y sociedad en el siglo XVI. La inquisición en Valencia, 1530-1609. Barcelona. 1980.

(3) J.B. VILAR, Orihuela, una ciudad valenciana en la España moderna. Murcia. 1981, 3 vols (IV, $\vee$ y VI de VILAR, Historia de la ciudad y obispado de Orihuela. Murcia. 1977-1982, 8 volsi. Vid. también VILAR, "Los moriscos de la gobernación y obispado de Orihuela", Al-Andalus, LXIII (1978), ps. 323-367; VILAR, "Moriscos granadinos en el Sur valenciano", Estudis, 9 (1983), ps. 15-47; VILAR, "Las 'ordinaçiones' del obispo Tomás Dassio, un intento de asimilación de los moriscos de la diócesis de Orihuela" en Les Morisques et leur temps. Paris. 1983, ps. 383-410; VILAR, "La rebelión y dispersión de los moriscos: el caso murciano», en Historia de la inquisición en España y América dirigida por J. PÉREZ VILLANUEVA. Madrid. 1984, ps. 772-780. 
bibliográficos españoles -Madrid, El Escorial y Valencia principalmente- y extranjeros -British Library, Bibliotheque Nationale de Paris-. Aún así la atribución no siempre es segura.

Apenas se sabe nada del destino final que corrieron las obras requisadas a los moriscos por los Tribunales inquisitoriales de Valencia y Murcia, de que existe referencia documental (4). Todo parece indicar que la mayor parte de esos depósitos fueron destruidos en fechas más o menos próximas a su incautación. En el mejor de los casos, vendidos o dispersados, perdiéndose los pocos conservados en sus archivos y anaqueles durante el asalto, saqueo y semidestruccción de las oficinas y establecimientos del Santo Oficio con ocasión de la abolición del Tribunal, según aconteció en Murcia.

A diferencia de lo ocurrido en Aragón (5) y, en menor medida, en Andalucía, el tardío hallazgo de bibliotecas moriscas en el pasado siglo, casi siempre al procederse a la reforma o demolición de algún viejo inmueble, ha sido en Valencia un hecho excepcional, en tanto en Murcia prácticamente inexistente. De donde el interés del descubrimiento en 1789 de una biblioteca morisca en Potries, inmediaciones de Gandía, acaso la primera de la serie en atención a la fecha del hallazgo, suceso al que en su momento no se dió publicidad alguna por las circunstancias que ahora referiremos, hasta el punto de pasar inadvertido.

En 12 de febrero de 1789 el ilustrado vecino de la ciudad de Gandía, don Joaquin Linares Martínez, se vió en la obligación de notificar al primer secretario de Estado, conde de Floridablanca, que en el lugar de Potries, a una legua de la urbe valenciana apuntada, "derribando una pared en la casa de Vicente Fuster, en el centro de aquella, se han encontrado dieciocho o veinte libros escritos al parecer en idioma arábigo, entre los cuales se advierte uno a manera de misal con cubiertas de vaqueta, muy bien correado, como si acabase de hacerse, y los otros de un tamaño regular, bastante correados, de modo que se conoce han sido colocados allí de estudio y con mucho cuidado, en donde es regular lo estén desde tiempo de los Moriscos, por ser dicho lugar otro de los que habitaban» (6).

Estimando Linares que las obras de referencia corrían peligro de ser destruidas por sus propietarios, modestos labradores incapacitados para valorar adecuadamente el posible valor del hallazgo, y conocedor del vivo interés mostrado por el ministro carolino en todo lo referente al fomento de las letras, las artes y las ciencias, y la preservación del patrimonio cultural del país, no dudó en poner el hecho en su conocimiento, "a fin [de que] se sirva (si le pareciere) dar comisión al exponente o a la persona de su superior agrado, para

(4) Vid. notas 2 y 3 supra

(5) Suele citarse como caso paradigmático el de Almonacid de la Sierra, a partir de la noticia inicial dada por don Francisco Codera. Vid. F. CODERA, "Almaçén de un librero morisco encontrado en Almonacid de la Sierran, Boletín de la Real Academia de la Historia, V (1884), ps. 269-276.

(6) Archivo Histórico Nacional [abreviamos A.H.N.], Estado (Marruecost, leg. $5818^{2}$ : Oficio de J. Linares Martínez al conde de Floridablanca, Gandía 12 febrero 1789 
que recoja dichos libros, y disponga su conducción a dicha Corte, donde con más facilidad pueden enterarse de ellos, y ver si contienen alguna noticia, o particularidad conveniente, o bien una vez que los tenga en su poder el comisionado o encargado, buscar éste sugeto que entienda el arábigo, que en $\mathrm{Va}$ lencia y Alicante los hay, y de lo que resultare, dar aviso a V. E. para disponer lo más conveniente" (7).

Nada sabemos del poseedor originario de esta biblioteca, posiblemente acomodado y culto propietario, o arrendatario, de la alquería donde fue hallada dos siglos después de su ocultación. Alguien como el célebre Moscayre, cadí de Gandía, con quien solía polemizar Bernardo Pérez de Chinchón en la época en que redactaba su «Antialcorán» (8), impreso en Valencia en 1532. Pero pudiera ser también alguno de los labradores moriscos de los alrededores de la localidad, a quienes Pérez de Chinchón prefería como contricantes en sus controversias, que no al bien preparado e irreductible Moscayre, por considerarles fácilmente silenciables (9). Acaso, en fin, alguien como el tendero Hoix (10) - ¿también almacenista de libros? - gentes que al margen de su variable condición social distaban de ser iletrados (11), y que en no pocos casos optaron en último extremo por el cambio religioso, la aculturación y la permanencia en el país (12).

Sea como fuere, el fondo bibliográfico de Potries es acaso el más importante de cuantos tenemos datados en el ámbito valenciano, y con honores de biblioteca si se le compara con hallazgos más modestos en otros puntos de la región. Supera, desde luego, al más notable de estos, exhumado casualmente en Albalat de Segart, o de Torongers, en marzo de 1904, conjunto de libros y papeles de interés diverso, escondido en el hueco de una de las paredes de la antigua ermita local, fondo adquirido por el bibliófilo José Martínez-Aloy, perteneciente hoy a sus herederos, y catalogado en su día por el arabista don Julián Ribera (13). Hallazgos posteriores se han dado junto al castillo de Vilavella en 1941 (14) y en Muro de Alcoy en 1951 (15), por mencionar dos casos bien conocidos, pero ambos de inferior interés al de Potries.

(7) ibidem

(8) L. CARDILLAC, Moriscos y cristianos. Un enfrentamiento polémico (1492-1640). Prefacio de F. Braudel. Madrid. 1979, p. 318.

(9) Ibidem, p. 323.

(10) Vid., por ejemplo, LABARTA, "Las cuentas del tendero morisco Gerónimo Hoix (Gandía, 1587)", AlQantara III (1982); p.p. 135-171.

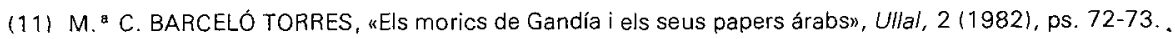

(12) J. SANCHIS COSTA, "Manifiesto de los moriscos que quedaron en Gandía en el año 1611", Anales de la Universidad de Alicante. Historia Moderna, 2 (1982), ps. 237-247).

113) Vid. J. RIBERA Y TARRAGO "Escuela valenciana de calígrafos árabes", Almanaque de "Las Provincias" (Valecia. 1907). Reimpreso en Ribera, Disertaciones y opúsculos. Madrid. 1928, 11, ps. 304-308. Más información sobre el hallazgo de Albalat en BARCELO TORRES, Minorias islámicas en el País Valenciano. Historia y dialecto. Valencia-Madrid. 1984, ps, 42, 47-48 y «Nuevos fondos arábigo-valencianos: la colección Martínez-Alcoy", A-Qantara, Madrid, Vly. 1986,321-330.

(14) BARCELÓ TORRES, Minorías..., p. 42 :

(15) lbidem, ps. 43 y 47 . 
La respuesta de Floridablanca a Linares no se dejó esperar. Debería adquirir el lote completo, remitiéndolo a continuación a Valencia, donde se haría cargo del mismo el marqués de Valera (16). Pese a instrucciones tan precisas, que sin duda fueron cumplidas, desconocemos el destino ulterior de los libros.

Acaso fueran depositados en alguna institución cultural valenciana, para terminar por ir a parar, en todo o en parte, a manos de algún bibliófilo, como don Vicente Hernández y Mañez, cuya valiosa colección se encuentra en la Biblioteca de la Universidad de Valencia. O bien, dispersados o no, tengan que ver con el antiguo fondo de libros y manuscritos árabes de la casa de Osuna, tan vinculada con el reino de Valencia, y singularmente con Gandía, hoy en la Biblioteca Nacional de Madrid y en otras entidades estatales beneficiarias del legado Osuna.

El que Linares no adjuntase inventario, dificulta todavía más cualquier pesquisa sobre el destino de los libros. Nos consta que se hallaban en excelente estado de conservación en el momento de ser encontrados. Uno de ellos, especialmente voluminoso y bien encuadernado, parece tratarse de un ejemplar del Corán. Estaban escritos en su totalidad en caracteres árabes, no pudiendo descartarse que figurara entre ellos algún texto aljamiado. Por último, aunque no se diga expresamente, es casi seguro que fuesen todos manuscritos.

El expediente en cuestión, reproducido íntegramente en los apéndices, se conserva entre la documentación española de finales del siglo XVIII referida a Marruecos, existente en la sección de Estado del Archivo Histórico Nacional, donde fue localizado por quien esto suscribe. Como quiera que sobre este asunto no hemos hallado ninguna otra referencia al término de una detenida exploración de los fondos de la expresada sección, como tampoco en las carpetas y legajos sobre Floridablanca también consultados en este y otros archivos, y ni siquiera noticia alguna en la "Gaceta de Madrid" de 1789, 0 en el "Diario de Valencia», que comenzó a salir en el siguiente año, como tampoco alusión ulterior al destino del hallazgo, todo parece indicar que el mencionado ministro recabase los servicios de alguno de los secretarios de cartas árabes adscritos al departamento de Estado, o de uno de los franciscanos arabófonos destinado en las misiones españolas existentes en varios puertos marroquíes, a quienes debieron remitirse los libros desde Valencia para su consulta, si es que el lote, una vez catalogado, en todo o en parte no fue incluido en alguna de las donaciones bibliográficas realizadas por Carlos IV al sultán Mulay Solimán.

(16) A.H.N., Estado (Marruecos), leg. 5818²; Floridablanca a Linares, Madria 27 febrero 1789. 


\section{APÉNDICE DOCUMENTAL}

1. Notificación del hallazgo al conde de Floridablanca (febrero, 1789) (1).

«Excmo. Señor.

Joaquín Linares Martínez, vecino de la ciudad de Gandía, reino de Valencia, a V.E. con el debido respeto expone y dice: Que en el lugar de Potries, distante de esta ciudad una legua, con corta diferencia, poco ha, derribando una pared en la casa de Vicente Fuster, en el centro de aquella, se han encontrado 18 o 20 libros escritos al parecer en idioma arábigo, entre los cuales se advierte uno a manera de misal con cubierta de vaqueta, muy bien correado (2), como si acabase de hacerse, y los otros de un tamaño regular, bastante correados, de modo que se conoce han sido colocados allí de estudio y con mucho cuidado, en donde es regular lo estén desde el tiempo de los Moriscos, por ser dicho luqar otro de los que habitaban.

El exponente, Excmo. señor, viendo que han dado en manos de labradores, que no se hacen cargo puedan ser útiles, y que es recelable si permanecen en su poder los rasguen o quemen, le ha parecido dar aviso de ello a V.E. (como lo hace) a fin [de que] se sirva (si le pareciere) dar comisión al exponente o a la persona de su superior agrado, para que recoja dichos libros, y disponga su conducción a dicha Corte, donde con más facilidad puedan enterarse de ellos, y ver si contienen alguna noticia, o particularidad conveniente, o bien una vez que los tenga en su poder el comisionado o encargado, buscar éste sujeto que entienda el arábigo, que en Valencia y Alicante los hay, y de lo que resultare, dar aviso a $\mathrm{V}$. E. para disponer lo más conveniente.

Dios Ntro. Señor guarde a V. E. $\mathrm{m}^{\mathrm{s}}$. $\mathrm{a}^{\mathrm{s}}$. con la mayor exaltación. Gandía 12 de febrero de 1789. Joaquín Linares Martínez.

Excmo. $5^{\text {or }}$ Conde de Floridablanca.»

2. El ministro acuerda la adquisición de la biblioteca por cuenta del Estado (febrero, 1789) (3).

Madrid 27 de febrero de 1789

«A D $D^{n}$ Joaquín Linares Martínez.

Gandía

Aprecio el aviso que $V$. m. me ha dado de haberse encontrado en el lugar de Potries, en el centro de una pared de la casa de Vicente Fuster, 18 o 20 libros escritos al parecer en idioma arábigo, entre los cuales se advierte uno a manera de misal, con cubiertas a baqueta; y encargo a $\mathrm{V}$. m. procure

(1) A.H.N., Estado (Marruecos), leg. $5818^{2}$ : Instancia de Linares a Floridablanca, Gandia 12 febrero 1789.

(2) Encuadernado en piel. 
adquiririos todos y ponerlos en poder del Marqués de Valera, en Valencia, dándome aviso de haberlo executado, y del coste que hubiese tenido esta diligencia.

Dios ... etc. [Floridablanca].» 